УДК 621.391 .27

\title{
ОЦЕНКА ЭФФЕКТИВНОСТИ СИСТЕМЫ СВЯЗИ, РАБОТАЮЩЕЙ В ПРЕРЫВИСТОМ РЕЖИМЕ
}

\author{
МАРИГОДОВ В. К., БАБУРОВ Э. Ф. \\ Севастопольский национальный технический университет, \\ Украина, Севастополь, 99053, ул. Университетская, 33
}

\begin{abstract}
Аннотация. Рассмотрена возможность построения системы связи, которая способна функционировать в условиях воздействия импульсных или сосредоточенных помех достаточно высокого уровня по сравнению с полезным сигналом. Для повышения помехоустойчивости таких систем предложен прерывистый режим работы, при котором информация передается только в такие временные промежутки, когда отношение сигнал-помеха выше пороговой величины. Приведен расчет эффективности предложенной системы по сравнению с известными
\end{abstract}

Ключевые слова: эффективность; помехоустойчивость; прерывистый режим работы; отношение сигнал-помеха; пороговая величина; синтезатор частот; перестройка несущих частот; канал управления

\section{ВВЕДЕНИЕ}

Известны системы связи, в которых повышение помехоустойчивости в условиях действия в канале радиосвязи флуктуационных, сосредоточенных и импульсных помех обеспечивается путем адаптивного предыскажения и корректирования сигналов [1-3]. В таких системах адаптация может осуществляться к изменяющемуся полезному сигналу, помеховой обстановке, а также к нестационарным радиоканалам.

Недостатки таких систем связи заключаются в том, что при действии в канале связи аддитивных флуктуационных, сосредоточенных и импульсных помех достаточно большого уровня, который в некоторых ситуациях может превышать уровень полезного сигнала, система связи обладает низкой помехоустойчивостью, а в некоторых случаях даже возникают перерывы связи. Кроме отмеченного, такие системы не обеспечивают требуемую помехо- устойчивость каналов прямого и обратного управления процессом перестройки адаптивных предыскажающих, компенсирующих, корректирующих и отбеливающих фильтров к непрерывно изменяющимся характеристикам сигналов, каналов и помех.

Для борьбы с мощными импульсными помехами целесообразно использовать известный метод бланкирования помех [4]. В некоторых случаях возможно применять прерывистый режим работы радиоканала, который находит практическое использование в метеорных линиях радиосвязи [5-7]. Такой режим целесообразен также в системах радиосвязи, которые функционируют при наличии в каналах помех достаточно большого уровня. При этом могут найти широкое применение методы обработки сигналов, которые используются при метеорной радиосвязи. Интересным представляется также использование при осуществлении прерывистой связи процесса перестройки 